\title{
More than "mountain guides" of science: a questionnaire survey of professional science communicators in Denmark
}

\author{
Kristian Hvidtfelt Nielsen
}

\begin{abstract}
This article sums up key results of a web-based questionnaire survey targeting the members of the Danish Science Journalists' Association. The association includes not only science journalists but also other types of science communicators. The survey shows that science communicators have a nuanced and multidimensional view on science communication, science, and technology. Science communicators are thus more than the "mountain guides" of science, as a recent definition describes it. The survey respondents are not just interested in helping the public at large to a wider recognition of scientific knowledge, but also want to contribute to democratic debate and social legitimisation of science and technology. The respondents exhibit a certain amount of optimism in relation to science and technology, yet also take a sceptical stance when confronted with overly positive statements regarding science and technology. Finally they have a predominantly social constructivist perception of science and technology when it comes to external relations to society, while they lean towards a hypothetical-deductive science understanding when it concerns the internal dynamics of science.
\end{abstract}

\section{Background}

Despite the growing interest of scientists, communicators, politicians, and others in communicating science, our research-based knowledge of the people who professionally attend to science communication is sparse. Research within the field of scientific communication has moved through three paradigms since the 1960's: "Science Literacy", "Public Understanding" and "Science and Society". All three paradigms have focused on the understanding of citizens and scientists, the content and media of science communication, or theories on science communication. The dismissal of the so-called "deficit model", according to which a chasm exists between scientists and citizens, is largely responsible for the lack of recognition of the active mediation between science and society that science communicators perform. This scientific neglect of a central group of key players in science communication could be one of the reasons that practicing science communicators do not take much interest in research into science communication. ${ }^{2}$

Science communication has been compared to mountain climbing. ${ }^{3}$ In this analogy it is lay people that move up the mountain towards higher "Science Literacy" and a better "Public Understanding of Science". The process demands skills, tools (ladders), activities, encouragement, and dialogue. The role of science communicators is simply described as that of "mountain guides":

They teach people how to climb (skills), provide ladders, assist with the actual climbing event (activities), and keep climbers informed about progress, possible dangers, and other issues related to the climb (dialogue). ${ }^{4}$

This widely spread and comparatively neutral view on how science communicators contribute to the process of science communication is challenged by some of the few existing studies focused on science communicators. In a questionnaire survey conducted amongst members of the National Association of Science Writers (NASW) and selected news- and science-editors, the respondents proved highly motivated to identify challenges and solutions pertaining to the future of science communication. Their major concern was related to "science literacy" and the need for new and more usable evaluation tools. 
Other challenges which were also mentioned were formal education of science communicators along with the risk of science communicators contributing to excessive "hype" around certain research disciplines or technologies. ${ }^{5}$ If we maintain the aforementioned mountain climbing metaphor, this means that the "mountain guides" were not readily willing to accept the size of the mountain, the ethics of mountaineering, and the way in which the mountaineers are guided up the mountain.

Other studies of science communicators have revealed other forms of doubt and uncertainty. An open, online questionnaire survey addressed to users of EurekAlert!, a web-based news service run by the American Association for the Advancement of Science, showed that many science communicators see the field of science communication as highly competitive. The respondents named the following four challenges as most important:

- Learning about science news before my competition

- Learning about science news before it becomes widely known to the public

- Judging the trustworthiness of research or researchers

- Finding researchers who can explain science so it's understandable ${ }^{6}$

The EurekAlert! survey also showed that the least challenging issue for the science communicators is to establish contact with researchers and research institutions. Together with other studies on researchers which have shown that researchers generally are quite willing to cooperate with science communicators, this dispels the myth that the relationship between researchers and science communicators is conflict-ridden. ${ }^{7}$

The NASW and EurekAlert! studies confirm that there is still a lot to learn about how science communicators perceive their own profession and subject area. It no longer suffices to fashion a definition of science communicators based purely on theoretical models of how science communication takes place. We need empirical studies which can teach us more about the "mountain guides" of science.

\section{Purpose}

The purpose of this survey is to obtain a deeper understanding of how science communicators view science communication and science. The survey aims to test the notion that science communicators themselves are actively involved in defining and querying the purpose, content, and criteria of success of science communication, a notion which is also apparent in the aforementioned studies. It is also the survey's purpose to explore science communicators' attitude towards their field of subject, namely science. Seeing as there are now indications that many more types of (positive) interactions exists between the realms of science and science communication, it will be expedient to find out whether it might be connected to the view science communicators hold on science and technology.

\section{Method}

The survey is based on the web-based SurveyXact $($ C system, developed and marketed by Rambøll Management. The system uses the Internet for online handling of questionnaire design, lists of respondents, distribution via e-mail, data collection, and data analysis.

The survey was carried out in collaboration with Danish Science Journalists' Association (Danske Videnskabsjournalister), which represents 164 science communicators in all. In the process of admission, the members have to provide documentation of their activities within the field of science communication. The association divides its members into four categories (however, no information about how many members fall into each category exist):

- Freelance journalists who write on technology and science

- Journalists at newspapers, magazines, and electronic news media, who particularly write on technology and science

- Information officers in government departments, committees, research institutions, and private companies who are engaged in science and technology

- Other professional communicators within the fields of technology and science, e.g. employees at science centres, etc.

The questionnaire was drawn up by the author. ${ }^{8}$ It contains three groups of questions, each consisting of seven questions with closed variables concerning the purpose, content, and criteria of success of science communication. These three groups of questions are all based on a Danish report on science 
communication published by the independent think tank Mandag Morgen (Monday Morning) and Danmarks Pædagogiske Universitetsskole (The Danish School of Education). ${ }^{9}$ In the report, the authors put forward seven different dimensions through which one can understand and evaluate science communication (see table 1).

\begin{tabular}{|c|c|c|c|}
\hline & Purpose & Content & Criteria of success \\
\hline Education & $\begin{array}{l}\text { Science communication } \\
\text { promotes the general } \\
\text { education of the population }\end{array}$ & $\begin{array}{l}\text { General knowledge on } \\
\text { science and technology }\end{array}$ & $\begin{array}{l}\text { Citizens' general } \\
\text { knowledge on science and } \\
\text { technology is increased }\end{array}$ \\
\hline Democracy & $\begin{array}{l}\text { Science communication is an } \\
\text { important aspect of the } \\
\text { common and democratic } \\
\text { public interest }\end{array}$ & $\begin{array}{l}\text { Ethical and political } \\
\text { issues regarding science } \\
\text { and technology }\end{array}$ & $\begin{array}{l}\text { More public debate on } \\
\text { subjects regarding science } \\
\text { and technology }\end{array}$ \\
\hline Legitimacy & $\begin{array}{l}\text { Science communication } \\
\text { increases the understanding or } \\
\text { acceptance of research and } \\
\text { innovation }\end{array}$ & $\begin{array}{l}\text { The importance of } \\
\text { science and technology } \\
\text { for society and culture }\end{array}$ & $\begin{array}{l}\text { Scientific research and } \\
\text { technological innovation } \\
\text { gain greater recognition } \\
\text { within the public at large }\end{array}$ \\
\hline Usefulness & $\begin{array}{l}\text { Science communication leads } \\
\text { to practical solutions - be } \\
\text { they commercial or societal }\end{array}$ & $\begin{array}{l}\text { Practical applications of } \\
\text { science and technology - } \\
\text { be they commercial or } \\
\text { societal }\end{array}$ & $\begin{array}{l}\text { Increase in practical uses } \\
\text { of science and technology }\end{array}$ \\
\hline $\begin{array}{l}\text { Cognition/ } \\
\text { Reflection }\end{array}$ & $\begin{array}{l}\text { Science communication is an } \\
\text { extra source of academic } \\
\text { cognition and reflection for } \\
\text { scientists and engineers }\end{array}$ & $\begin{array}{l}\text { Reflective knowledge } \\
\text { about processes of } \\
\text { cognition within the } \\
\text { fields of science and } \\
\text { engineering }\end{array}$ & $\begin{array}{l}\text { Stimulation of academic } \\
\text { cognition and reflection } \\
\text { amongst scientists and } \\
\text { engineers }\end{array}$ \\
\hline Resources & $\begin{array}{l}\text { Science communication } \\
\text { attracts resources to a given } \\
\text { area of research or innovation }\end{array}$ & $\begin{array}{l}\text { Focus is on specific areas } \\
\text { of research and } \\
\text { innovation }\end{array}$ & $\begin{array}{l}\text { More funds earmarked for } \\
\text { scientific research and } \\
\text { technological innovation }\end{array}$ \\
\hline Career & $\begin{array}{l}\text { Science communication } \\
\text { promotes the career of certain } \\
\text { researchers and engineers }\end{array}$ & $\begin{array}{l}\text { Focus on the work and } \\
\text { results of named } \\
\text { researchers and engineers }\end{array}$ & $\begin{array}{l}\text { Researchers and engineers } \\
\text { gain more visibility in the } \\
\text { media }\end{array}$ \\
\hline
\end{tabular}

Table 1. Seven dimensions of science communication and their impact on purpose, content, and criteria of success. ${ }^{10}$

In addition, the questionnaire contains two groups of questions, each with ten sub-questions translated from a Eurobarometer survey on the Europeans' attitudes towards science and technology. ${ }^{11}$ The first group of questions relates to optimism or scepticism towards science and technology. The second group of questions focuses on the relation between science, technology and society.

Three pilot tests of the whole questionnaire were carried out with the following three groups of respondents: 1) a university-based group of researchers with interest in science didactics and science communication, 2) the board of the association, 3) a specially selected project monitor group consisting of representatives for the above-mentioned four categories of members in the association. The answers from the three pilot groups were used to improve the questions in regards to formulation, possible misunderstandings, and factual errors.

As a result of the pilot testing with group no. 1, three open answer categories regarding the respondents' perception of science, experiment, and technology were added to the survey. A single open question comparing a social constructivist view on science versus a more classic positivistic view was also included.

The questionnaire was sent out to the members of the association on April 29, 2009, with a two week deadline of completion. The invitation to participate contained a short introduction of the purpose of the survey and contact information. A link to the questionnaire was also included, causing the questionnaire to open in another window. All respondents received a personal identification number and all answers were anonymous. The actual questionnaire took 15-20 minutes to complete. Three days before the deadline, those who had still not responded received a reminder. After the deadline expired, an extension of three working days was offered. 
In all, 54 fully completed and 20 partially completed responses form the basis of the survey. According to the standard definitions of the American Association for Public Opinion Research, this corresponds to response rates of 33\% (Response Rate 1) and 45\% (Response Rate 2). ${ }^{12}$

\section{Results}

Almost half the respondents (48\%) state that they work as freelance and/or are self-employed. The rest either work in a public organisation $(32 \%)$ or in the private sector $(20 \%)$. Nearly half of the respondents have a university degree within the natural sciences $(46 \%)$, while just under one third $(30 \%)$ have another type of university degree (within the humanities or social sciences). About one sixth (16\%) have completed a higher education in journalism. These figures indicate that we have two separate groups of respondents with a higher education: one group with a background in science and one group with a background in the humanities/social sciences/journalism. Almost one quarter (24\%) report that they have qualifying supplementary training in journalism and/or communication. Our respondents are $43 \%$ female and $57 \%$ male.

There is very little consistent information available about all members of the association. Member information is maintained by a database, which is being kept up-to-date by the members themselves. Consequently, it's very difficult to compare for representativeness respondents with non-respondents. Based on the information provided online by the association, we do know that women account for $49 \%$ of the association's members. We also know that about half of the members state that they are either freelance and/or self-employed, while approximately one-third work for public research organisations and/or bodies. These figures correspond well with the equivalent percentages found in our group of respondents, although they probably are not evidence for representativeness across other background variables such as age and education about which we have no consistent information for all members of the association. This said, we may conclude that with respect to gender and employment our group of respondents is representative for all members of the Danish Science Journalists' Association.

Table 2 shows the respondents' estimation of the seven dimensions of science communication according to the significance the dimensions should hold for purpose, content, and criteria of success of current science communication. The estimation is based on a five point scale, where 1 denotes very high significance and 5 denotes very low significance. As is evident in table 2, Education and Democracy are consistently allotted the highest significance in all three categories while Cognition/Reflection, Resources, and Career are given the lowest significance. Legitimacy is ranked third in purpose and criteria of success. Usefulness is placed third in content, whereas Legitimacy is pushed to fourth in the same category.

\begin{tabular}{|l|l|l|l|}
\hline & Purpose & Content & Criteria of success \\
\hline Education & $\mathbf{1 . 9}$ & $\mathbf{2 . 1}$ & $\mathbf{1 . 9}$ \\
& $(1.7)(2.2)$ & $(1.8)(2.4)$ & $(1.6)(2.4)$ \\
\hline Democracy & $\mathbf{2 . 0}$ & $\mathbf{2 . 2}$ & $\mathbf{2 . 1}$ \\
& $(1.8)(2.6)$ & $(2.0)(2.4)$ & $(1.9)(2.4)$ \\
\hline Legitimacy & $\mathbf{2 . 3}$ & $\mathbf{2 . 1}$ & $\mathbf{2 . 3}$ \\
& $(2.0)(2.9)$ & $(1.9)(2.5)$ & $(2.1)(2.9)$ \\
\hline Usefulness & $\mathbf{2 . 9}$ & $\mathbf{2 . 3}$ & $\mathbf{2 . 4}$ \\
& $(2.8)(3.1)$ & $(2.3)(2.5)$ & $(2.5)(2.4)$ \\
\hline Cognition/Reflection & $\mathbf{2 . 8}$ & $\mathbf{2 . 7}$ & $\mathbf{2 . 7}$ \\
& $(2.8)(2.9)$ & $(2.6)(3.0)$ & $(2.6)(2.7)$ \\
\hline Resources & $\mathbf{3 . 4}$ & $\mathbf{3 . 2}$ & $\mathbf{2 . 7}$ \\
& $(3.0)(3.2)$ & $(3.1)(3.4)$ & $(2.5)(3.2)$ \\
\hline Career & $\mathbf{3 . 8}$ & $\mathbf{3 . 5}$ & $\mathbf{2 . 9}$ \\
& $(3.6)(3.9)$ & $(3.3)(3.7)$ & $(2.9)(3.2)$ \\
\hline
\end{tabular}

Table 2. Average values (in bold) for the significance of the seven dimensions of science communication (see table 1) according to the significance of each of the dimensions for purpose, content, and criteria of success of current science communication $(1=$ very high significance... $5=$ very low significance). The figures in the first parentheses represent respondents with a background in the natural sciences, and the figures in the second parentheses represent respondents with a background in humanities/social science/journalism. 
Table 2 suggests that the respondents ascribe science communication higher significance in relation to the public than in relation to science and technology. Whereas Cognition/Reflection, Resources, and Career all are elements which benefit the fields of science and technology in the shape of increased insight and more funds, Education, Democracy, and Usefulness all are elements that have an effect on the surrounding society. Legitimacy is a possible exception to this observation, though. Increased public recognition of the importance of science and technology for society and culture, may, to a large degree, have immediate positive consequences for science and technology. Likewise it may also be instrumental in increasing the societal usefulness of science and technology.

We observe that natural science respondents generally attribute higher significance to science communication than respondents coming from the humanities/social science/journalism. This is the case for all seven dimensions and across the three categories: Purpose, Content, and Criteria of success. In other words, although they share a positive view of the general importance of science communication, there is a trend towards increased scepticism or even criticism among respondents who have a higher education within the humanities, the social sciences, and journalism compared to respondents with a higher education in the natural sciences.

The respondents further nuance their view on science, technology and society by indicating their position on 20 statements regarding science and technology. The statements were selected from a Eurobarometer survey conducted in 2005. The respondents were asked to state agreement or disagreement on a five point Likert-scale, where 1 is strongly agree and 5 is strongly disagree.

The first ten statements all relate to an optimistic or critical stance in regards to science and technology. There was an attempt to order the statements in terms of increasing optimism towards science and technology. Q1 is thus the most negative statement and Q10 is the most optimistic.

- Q1: Science and technology cannot really play a role in improving the environment

- Q2: Science and technology are responsible for most of the environmental problems we have today

- Q3: A discovery is in itself neither good nor bad, it is only the way the discovery is used which matters

- Q4: Scientific and technological progress will help to cure illnesses such as AIDS, cancer etc.

- Q5: Thanks to science and technology, there will be more opportunities for future generations

- Q6: The benefits of science are greater than any harmful effects it may have

- Q7: Science and technology will make our lives healthier, easier and more comfortable

- Q8: Science and technology will help eliminate poverty and hunger around the world

- Q9: Thanks to scientific and technological advances, the Earth's natural resources will be inexhaustible

- Q10: Science and technology can sort out any problem

The next ten statements are concerned with the relation between science, technology, and society. The statements were ordered to reflect an increase in the relevance of relations between science and technology, on one side, and society (citizens and politicians) on the other side. Q11-15, thus, are statements which maintain a certain autonomy or status quo in the relation between science, technology, and society. Q16-20 all suggest possible interrelations, while Q15-17 deal more specifically with the question of the precautionary principle.

- Q11: Science and technology do not play a role in industrial development

- Q12: Basic scientific research is not essential for the development of new technologies

- Q13: The public is sufficiently involved in decisions about science and technology

- Q14: Research conducted by industry is well controlled and regulated

- Q15: There should be no limit to what science is allowed to investigate

- Q16: If we attach too much importance to risks that are not yet fully understood, we will miss out on technological progress

- Q17: If a new technology poses a risk that is not fully understood, the development of this technology should be stopped even if it offers clear benefits

- Q18: Only by applying the most advanced technologies can our economy become more competitive

- Q19: Even if it brings no immediate benefit, scientific research which adds to knowledge should be supported by government

- Q20: Politicians should rely more on the advice of expert scientists 


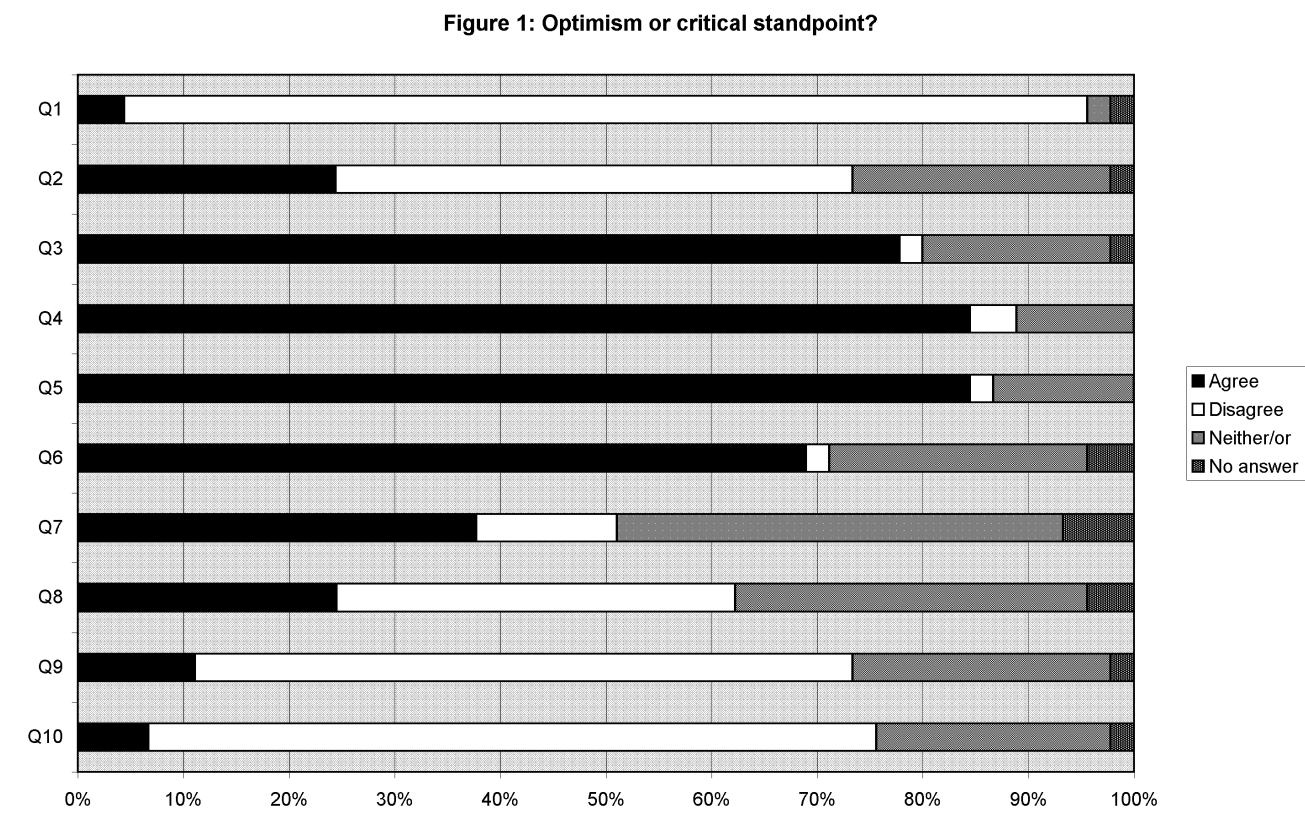

Figure 1. The respondents' indications of agreement with the statements in Q1-10 regarding optimism or a critical standpoint on science and technology.

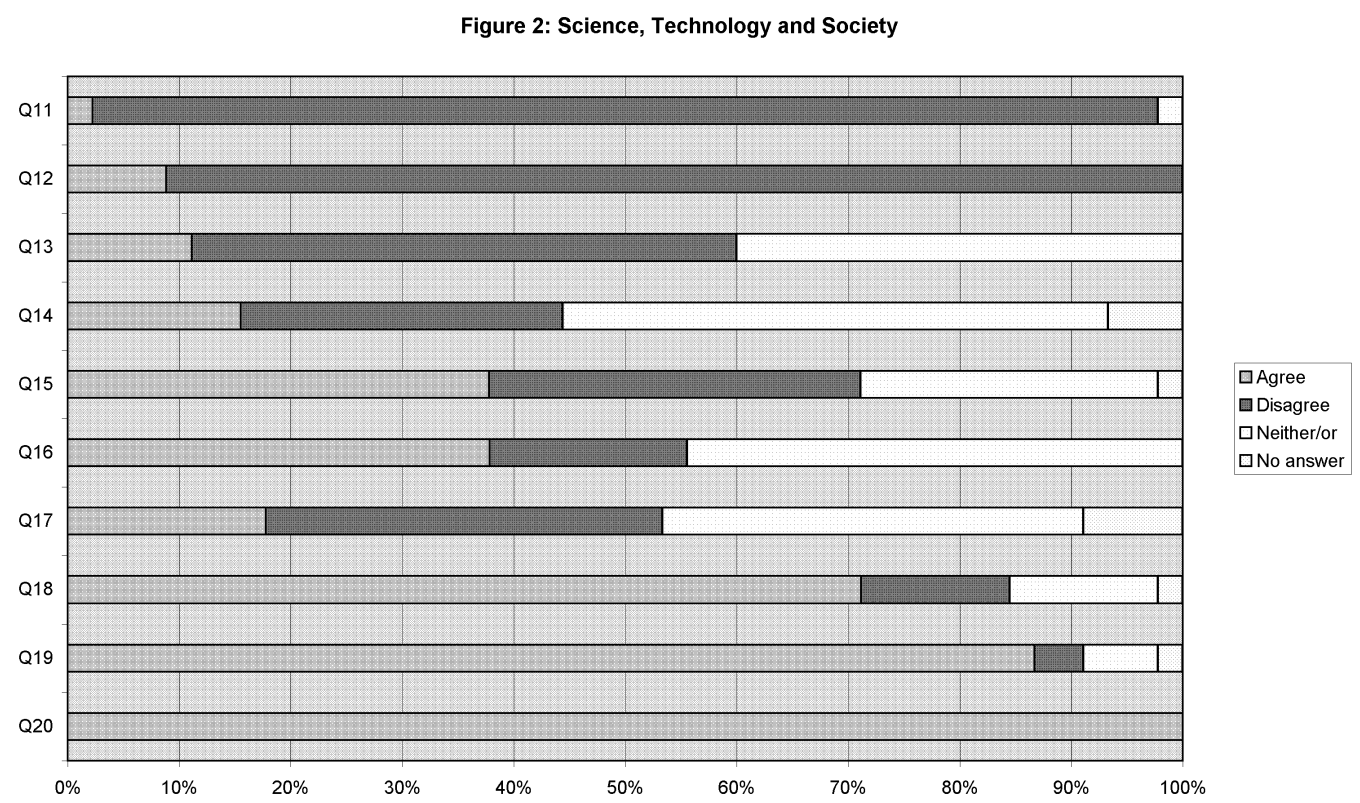

Figure 2. The respondents' indications of agreement with the statements Q11-20 regarding the relevance of the relation between science, technology, and society.

Figure 1 shows that the highest degree of agreement among the respondents is with the statements in Q3-6. The level of agreement with the two statements most critical to science, Q1+2, is only around $10 \%$. The same goes for the most optimistic statements in Q9+10. This suggests that the respondents are comparatively optimistic about the role of science and technology in solving important social problems. At the same time, they exhibit what might be interpreted as a healthy scepticism towards highly critical and glibly optimistic statements on science and technology. 
Figure 2 shows a tendency towards greater agreement with statements indicating intimate relations between science, technology, and society. A large majority of the respondents seem to agree that politics, state, public, and economy are closely tied to scientific research, technological innovation, and expertise.

Q15-17 are statements on precautionary measures in relation to science and technology. Here the respondents are more divided. For example, the agreement and disagreement answers are in equal numbers on the statement that there should be no limit to what science is allowed to investigate. On the other hand, there is predominant agreement with the statement that technology should not be stopped unnecessarily because of risks that are not yet fully understood.

Looking for variances in the responses to Q1-20, we note slight trends in respondents with a background in humanities/social sciences/journalism being a little more sceptic concerning science and technology as well as indicating more connections between science, technology, and society than respondents from the natural sciences. This trend is visible in most (but not all) responses. The most obvious difference between the two groups of respondents is seen in responses to Q14. Whereas $21 \%$ of all respondents with a background in the natural sciences agree with the statement that "research conducted by industry is well controlled and regulated", the same applies to only $5 \%$ of respondents educated in the fields of the humanities, the social science, and journalism. However, the trend is not clear. For example, respondents from humanities/social sciences/journalism agree more strongly than respondents from the natural sciences with statement Q13 about citizens being sufficiently involved in decisions about science and technology. This indicates that such respondents have a slightly more positive view on existing efforts at public engagement in science.

The survey also asks respondents to express their perceptions of science and technology. To this end there are two different question categories. In the one category, the respondents were asked to describe in their own words: 1) what constitutes scientific research, 2) what constitutes a scientific experiment, 3) how is new technology developed. In the other category, the respondents were asked to take a position on two different perceptions of science: social-constructivism and a classic perception of science as being free from social and cultural influences.

For the latter issue, almost half of the respondents' (45\%) answers state that they lean towards an inclusion of both perceptions. Close to one third (36\%) point to the social-constructivist perception, while only a little over one in ten (14\%) is of the positivist/objectivist conviction. $5 \%$ of the respondents failed to answer the question.

The attitude including both perceptions is expressed in written replies such as these:

The purpose of science is to rise above society and present knowledge of objective nature. However the funds with which to conduct research are granted by society. Recently, science has become politicized, especially with respect to climate and intelligence research.

Developments in 'hard sciences' will reflect social and political values, in so far as the branch of science is new, and/or where there are few powerful centres or researchers in the field. But when the field of research becomes more international, the local values become weaker.

On the questions regarding what constitutes scientific research, what constitutes a scientific experiment, and how new technology is developed, the answers also exhibit great nuance. The table below lists the main aspects pointed out by respondents.

Table 3 reveals a large diversity in the perception the respondents have of scientific research, experiments, and technological innovation. Taken together, the answers testify to a wide and multifaceted range of perceptions on science and technology amongst the respondents. One can reasonably assume that this breadth of perception expresses itself in the collective work of science communicators.

But the answers are far from representative of all the respondents. In reality most of the statements only represent a few science communicators' views on science and technology. When it comes to scientific research and experiments, the requirement of drawing up and examining a hypothesis and/or a theory is pointed out the most. Almost half of the respondents (47\%) explicitly mention the hypothesis as part of what they see as proper scientific research and experiments. No other statement was mentioned by more than $10 \%$ of the respondents. On the question of technological development, most respondents agree with the statement that innovation primarily consists of applying results of basic research. Over half of the respondents $(64 \%)$ declare themselves in agreement with this viewpoint. 


\begin{tabular}{|c|c|}
\hline $\begin{array}{l}\text { Doing scientific } \\
\text { research amounts to: }\end{array}$ & $\begin{array}{l}\text { - Drawing up and examining a hypothesis and/or theory } \\
\text { - Requiring openness, honesty, methodology, and control } \\
\text { - Using statistics and large amounts of data } \\
\text { - Requirements of reproducibility and measurability } \\
\text { - Using scientific methods } \\
\text { - Founding explanations on facts } \\
\text { - Increasing scientifically recognised knowledge }\end{array}$ \\
\hline $\begin{array}{l}\text { A scientific } \\
\text { experiment consists } \\
\text { of: }\end{array}$ & $\begin{array}{l}\text { - Examination of hypothesis and/or theory } \\
\text { - Laboratory and field work, computer simulations, quantitative and } \\
\text { qualitative interviews } \\
\text { - Testing new experimental equipment } \\
\text { - Based on already concluded experiments, demarcation of the research } \\
\text { area, preconditions and sources of error } \\
\text { - Examine the relation between various variables } \\
\text { - Requirements of reproducibility and measurability }\end{array}$ \\
\hline $\begin{array}{l}\text { Developing new } \\
\text { technologies is: }\end{array}$ & $\begin{array}{l}\text { - Applying basic research results } \\
\text { - Driven by user defined and/or society created needs } \\
\text { - Driven by commercial interests } \\
\text { - A creative process } \\
\text { - An incremental, linear process from idea to pilot test to market } \\
\text { introduction } \\
\text { - Complex processes, which involve a variety of interests: political, } \\
\text { research, commercial, ethical, individual, etc. } \\
\text { - Further development of existing technologies } \\
\text { - Development of ideas is jointly carried out between researchers in the } \\
\text { private sector, at universities, and technology-oriented research } \\
\text { institutions; product development is carried out in the private sector }\end{array}$ \\
\hline
\end{tabular}

Table 3. Answers to the open questions on scientific research, experiments, and technological innovation.

\section{Conclusion}

The survey on the members of the Danish Science Journalists' Association has resulted in new knowledge about science communicators' attitudes towards and views on science communication, science and technology. The aim of this conclusion is to sum up and put the results into perspective and thus to contribute to the discussion on science communicators as "mountain guides" of science, the metaphor mentioned in the beginning of the article.

The survey has shown that the respondents primarily view science communication as an aspect of an educational, democratic, and legitimising process in society, see table 2. The role of science communication as promoting cognition, career, and available resources of researchers and scientists only has secondary importance. These findings indicate that science communicators first and foremost take the needs of their audience, the public, into consideration. This result is consistent with the survey carried out amongst the members of NASW, which concluded that "science literacy" and "the problem of science learning" ranked amongst the most pressing matters for science communicators. ${ }^{13}$

The conclusion is supported by the answers given to the ten questions on science, technology, and society, shown in figure 2. From these answers we conclude that our respondents perceive science and technology as being fully integrated aspects of society and culture. Thus, there is complete agreement $(100 \%)$ with the statement that experts in scientific disciplines should be involved to a higher degree in political decision making. Likewise, there is wide support of the view that the government should fund basic research, also in cases where the research is not immediately applicable. The latter conclusion could be linked to the perception that technological development is mainly built upon applied basic research, a view shared by over half of the respondents, see table 3 .

We observed indications that, although quite positive towards science and technology, respondents educated within the humanities/social sciences/journalism expressed more scepticism and more criticism 
than respondents with a background in the natural sciences. We stress that these trends are indications that needs to be explored more carefully in future research. We provide one obvious explanation or hypotheses relating to this trend: the positive view that (most) natural scientists have toward science and its wider communication, combined with the tradition of critical distance and interpretation in other academic disciplines and in journalism.

Furthermore, this survey has shown that even though generally the respondents do have a positive attitude towards the potential of science and technology, they still are critical of very optimistic statements about this potential. This is also the case in the NASW survey, where the respondents opposed the exaggerated use of hype and alarmism in science communication, as in the Eurobarometer survey indicating that Europeans are positive, yet critical towards science and technology. ${ }^{14}$

The same conclusion applies to the populations of Europe. The Eurobarometer survey from 2005 concludes:

Results show that Europeans are very optimistic concerning science and technology for certain aspects as well as somewhat sceptic for others. Although it may bring benefits, Europeans do not place too high hopes in science and technology to solve all the world's problems. ${ }^{15}$

The respondents express many different views on what constitutes scientific research, scientific experiments, and technological development, though some common agreement exist. Around half of the respondents point out that scientific research and experiments are dependent on the formulation and testing of a hypothesis and/or theory, while technological development is mainly built on basic research.

The above views are to some extent in diametrical opposition to the idea that science can be perceived as being both social-constructivist and positivist, a perception that was also expressed by half of the respondents. This discrepancy can probably be explained to some degree by the fact that respondents make a distinction between two aspects of science: on one hand, they contemplate the internal dynamics of science, which are seen as being controlled by a hypothesis/theory test, and, on the other hand, they think about science and its external relations, where the relations between science, technology, and the surrounding society determine scientific development. In regards to the external dynamics of science the respondents lean towards a social-constructivist viewpoint.

Seen as a whole, the results of the survey further stresses the question whether it is appropriate to simply regard science communicators as the "mountain guides" on the trails of the high mountain of science understanding. We believe our results show that science communicators do not just regard themselves as guides who help the public in its search for more and higher understanding of scientific knowledge. Science communicators can also be instrumental in the inclusion of the sciences in a broader social and democratic context, along with disseminating nuanced perceptions of the dynamics of science, technology, and society.

\section{Acknowledgments}

This study was funded by the Danish Council for Independent Research | Humanities, Grant no. 2129-070001. The author would like to thank the board of the Danish Science Journalists' Association for its cooperation, facilitated by Michael de Laine (chairman of the board).

\section{Notes and references}

1 M.W. Bauer, N. Allum and S. Miller (2007), What can we learn from 25 years of PUS survey research? Liberating and expanding the agenda, Public Understanding of Science 16(1): 79-95.

2 S. Miller (2008), So Where's the Theory? On the Relationship between Science Communication Practice and Research, in D. Cheng, M. Claessen, T. Gasgoigne, J. Metcalfe, B. Schiele and S. Shi (eds.), Communicating Science in Social Contexts, Berlin, Springer Science Business Media, p. 275-287.

3 T.W. Burns, D.J. O'Connor and S.M. Stocklmayer (2003), Science communication: a contemporary definition, Public Understanding of Science 12: 183-202.

4 T.W. Burns, D.J. O’Connor and S.M. Stocklmayer, op. cit., p. 194. 
5 D. Treise and M.F. Weigold (2002), Advancing science communication - A survey of science communicators, Science Communication 23(3): 310-322.

${ }^{6}$ G. Pinholster and C. O'Malley (2006), EurekaAlert! survey confirms challenges for science communicators in the post-print era, JCOM 05(03): C1, retrieved June 28, 2009; available at: http://jcom.sissa.it/archive/05/03/Jcom0503\%282006\%29C05/Jcom0503\%282006\%29C01.

7 H.P. Peters et al. (2008), Science-Media Interface It's Time to Reconsider, Science Communication 30(2): 266-276;

K.H. Nielsen, C.R. Kjaer and J. Dahlgaard (2007), Scientists and science communication: a Danish survey, JCOM 06(01): A01, retrieved June 29, 2009; available at: http://jcom.sissa.it/archive/06/01/Jcom0601\%282007\%29A01/.

8 The questionnaire is available on request from the author.

9 Mandag Morgen and Danmarks Pædagogiske Universitetsskole, Jagten på det trovardige universitet, Copenhagen, Mandag Morgen (2005).

${ }^{10}$ Adjusted from Mandag Morgen and Danmarks Pædagogiske Universitetsskole, op. cit., fig. 4, p. 19.

${ }^{11}$ European Commission, Europeans, Science and Technology. Special Eurobarometer 224, Brussels: European Commission, 2005. Retrieved June 24, 2009; available at: http://ec.europa.eu/public opinion/archives/ebs/ebs 224 report en.pdf.

${ }^{12}$ American Association for Public Opinion Research, Standard Definitions. Final Definitions of Case Codes and Outcome Rates for Surveys, revised 2008, Retrieved June 24, 2009; available at: http://www.aapor.org/2222.

${ }_{13}$ Treise and Weingold, op. cit., p. 316-17.

${ }^{14}$ Treise and Weingold, op. cit., p. 318

${ }^{15}$ European Commission, op. cit., p. 53.

\section{Author}

Kristian Hvidtfelt Nielsen is associate professor in the history of science and science communication at the Department of Science Studies, Aarhus University, Denmark. His project on science communicators in Denmark also includes semi-structured interviews with science communicators and a web-based questionnaire survey of museum educators. E-mail: khn@ivs.au.dk.

How TO CITE: K.H. Nielsen, More than "mountain guides" of science: a questionnaire survey of professional science communicators in Denmark, Jcom 09(02) (2010) A02. 